\title{
Clinical effects of two combinations of olfactory agents on olfactory dysfunction after upper respiratory tract infection during olfactory training
}

\author{
ID Xiao-Feng Qiao"\# \\ (iD) Yin-Huan Bai ${ }^{1 \#}$ \\ (iD) Guo-Ping Wang \\ (iD) Xin $L i^{2}$ \\ (D) Wei Zheng ${ }^{1}$
}

1. Department of Otorhinolaryngology, Shanxi Provincial People's Hospital Affiliated to Shanxi Medical University, Taiyuan 030001, China
2. Department of Surgery, Children's Hospital of Shanxi Province, Taiyuan 030001, China
\# These authors contributed equally to this study

http://dx.doi.org/10.1590/1806-9282.66.1.18

\begin{abstract}
SUMMARY
OBJECTIVE: To compare two combinations of olfactory agents for olfactory training therapy of olfactory dysfunction after upper respiratory tract infection (URTI) and investigate the influencing factors on clinical effects.

METHODS: 125 patients with olfactory dysfunction were randomly divided into two groups: test and control. During the olfactory training, four odors were used in both groups. The olfactory training lasted for 24 weeks. Then, participants were tested using Sniffin' Sticks and threshold-discrimination-identification (TDI) composite scoring before treatment and at 1, 3, and 6 months after treatment. The TDI scores were compared at different time points between the groups and within them, and influence factors were analyzed.

RESULTS: There was no significant difference in TDI scores between both groups. Furthermore, TDI scores did not significantly change after one month of treatment in either of the groups. After 3 and 6 months of treatment, TDI scores both significantly increased, and the odor discrimination and identification abilities significantly strengthened in both groups; however, the odor thresholds did not improve. The course of the disease was a significant influencing factor on the therapeutic effect of olfactory training for both groups.

CONCLUSION: The combination of essential balm, vinegar, alcohol, and rose perfume for olfactory training, which are scents commonly found in daily life, can effectively cure URTI-induced olfactory dysfunction, and significantly improve the odor discrimination and identification abilities. Furthermore, prolonging the treatment time can help with the recovery of olfactory functions, and earlier olfactory training can improve the therapeutic effect.
\end{abstract}

KEYWORDS: Olfaction Disorders. Olfactory Perception. Training. Smell/physiology. Infection.

\section{INTRODUCTION}

Olfactory dysfunction is a common symptom during otolaryngology outpatient service and is mainly induced by three causes, including upper respiratory tract infection (URTI), nose and sinus diseases, and head injuries. In particular, the incidence rate of secondary olfactory dysfunction after URTI is $37.9 \%{ }^{1}$ During the clinical treatment of secondary olfactory dysfunction after URTI, and in addition to drug 
treatment, olfactory training has attracted growing attention in recent years. In this new therapy of olfactory training, the recovery of olfactory functions is promoted through the periodical and repeated active smelling of diverse everyday odors. Clinical studies have indicated that this training is beneficial for the olfactory functions in olfactory dysfunction patients..$^{2-5}$ The conventional olfactory agents used in olfactory training are mostly standardized reagents produced by specialized corporations but are limited by the need for purchase and the inconvenience of using and carrying them. In the present prospective study, four accessible odors common in daily life (essential balm, vinegar, alcohol, and rose perfume) were selected, and the therapeutic effects and influence factors during olfactory training on post-URTI olfactory dysfunction were investigated.

\section{DATA AND METHODS}

\section{Clinical data}

A total of 131 outpatients with URTI-induced olfactory dysfunction treated at the Department of Otolaryngology at Shanxi People's Hospital between December 2015 and August 2018 were enrolled in the present study. These patients were randomly divided into two groups, according to the combinations of olfactory agents: test group and control group. The present study was approved by the Ethics Committee of the hospital. All subjects included provided signed informed consent.

The inclusion criteria were as follows: (1) definite history of URTI and secondary olfactory dysfunction after infection, without a blank period between the two, and the course of olfactory dysfunction was $\leq 24$ months; (2) detailed inquiry of medical history to exclude history of traumas, Alzheimer's disease, Parkinson's disease, mental diseases, and immune diseases; (3) nasal endoscopic examination to eliminate nasal neoplasm, nasal sinusitis, allergic rhinitis, olfactory cleft edema, and other nasal diseases; (4) sinal computed tomography (CT) and head magnetic resonance imaging (MRI) to exclude space-occupying diseases in the nasal cavity, sinus and intracalvarium, as well as neurodegenerative diseases; (5) uncured by medication of glucocorticoid, gingko extracts, or vitamin $\mathrm{A}$, and time of drug therapy was $>1$ month.

The exclusion criteria were as follows: contraindication to therapeutic method or drugs; interruption due to intolerance or adverse reactions during therapy; development of other diseases or need of other drugs that might interfere with the therapeutic effects.

\section{Methods}

Medical data collection

Information was collected from all patients included via questionnaire, including gender, age, body mass index (BMI), course of diseases, history of smoking/drinking, history of diabetes, history of hypertension, combination with taste dysfunction, and visual analog scale (VAS) score.

\section{Olfactory function test}

Sniffin' Sticks (Burghart, Germany) were used in the tests before treatment and at 1, 3, and 6 months after treatment. This test involved three parts: (1) odor threshold test, with a score ranging from $O$ (even the highest concentration cannot be discriminated) to 16 (the lowest concentration can be discriminated); (2) odor discrimination test (a score of 16 mean that all odors can be discriminated); (3) odor identification (a score 16 mean that all odors can be identified). After the three parts of tests, the scores for odor threshold (T), odor discrimination (D), and odor identification (I) were added together, and the result was the threshold-discrimination-identification (TDI) score used to evaluate olfactory function.

\section{Therapeutic scheme}

The olfactory training involved four odors in the test group (essential balm, vinegar, alcohol, and rose perfume) and control group (phenyl ethanol-rose, menthol-mint, citronellal-lemon, and eugenol-clove) (Sigma-Aldrich, USA). During the treatment, each olfactory agent was smelled for 10 seconds/time, and the interval between two olfactory agents was 10 seconds. Each olfactory training lasted for five minutes, and the training frequency was one time before breakfast, and another time before sleep every day. ${ }^{6}$ Olfactory function was tested at 1,3 , and 6 months after treatment.

\section{Therapeutic effect assessment}

The therapeutic effect was assessed by the variation in mean TDI scores after the treatment. A variation of $>6$ was considered as "effective". ${ }^{7}$

\section{Statistical analysis}

Statistical analysis was conducted on SPSS 20 . With the clinical effect as the dependent variable, 
Logistic regression analyses were performed with the independent variables of gender, age, BMI, course of diseases, history of smoking/drinking, history of diabetes, history of hypertension, combination with taste dysfunction, and VAS score. The TDI scores before and after treatments were compared between groups via paired t-test.

\section{RESULTS}

\section{Basic information}

Among the 136 patients (68 patients in each group), 11 patients (eight patients from the control group and three patients from the test group) were excluded due to treatment interruption (nine patients for reasons such as being on business) or missed follow-up (two patients). Finally, 65 tested cases and 60 controls were included in the present study. In the test group, the 66 patients comprised 21 males and 44 females. Their ages ranged within 18-66 years old $(50.2 \pm 13.5$ years old), and their course of diseases lasted within 6.0-22.0 months $(11.9 \pm 4.8$ months $)$. The numbers of patients with a BMI of $\geq 24$, a history of drinking, diabetes, hypertension, and complication by taste dysfunction were 21 (32.3\%), 10 (15.4\%), 13 (20.0\%), $18(27.7 \%)$, and $20(30.8 \%)$, respectively. The VAS score was $4.18 \pm 1.84$. In the control group, the 60 subjects comprised 20 males and 40 females. Their ages ranged within $25-65$ years old ( $52.4 \pm 12.3$ years old), and their course of diseases lasted within 6.0-21.0 months (13.4 \pm 4.8 months). The numbers of patients with a BMI of $\geq 24$, a history of drinking, diabetes, hypertension, and complication by taste dysfunction were 22 (36.7\%), 11 (18.3\%), 14 (23.3\%), 17 (28.3\%), and 19 (31.7\%), respectively. The VAS score was $4.13 \pm 1.87$. In terms of age and gender, the patients included were mostly old women ( $67.2 \%$ females). This was consistent with another study that reported that URTI-induced olfactory dysfunction mostly affects women over 50 years old. ${ }^{8}$ Olfactory dysfunction was dominated by hyposmia and anosmia (test group: 47 and 18 patients, respectively; control group: 43 and 17 subjects, respectively). The TDI scores were dominated by the deterioration of olfactory identification ability. ${ }^{9}$

\section{Clinical therapeutic effect}

The effectiveness rates at 1,3 , and 6 months after treatment were $3.08 \%, 26.15 \%$, and $41.54 \%$, respectively, in the test group, and $1.67 \%, 26.67 \%$, and $41.67 \%$, respectively, in the control group. No significant difference in TDI scores was found between both groups at any time point $(P>0.05)$. Furthermore, the TDI scores did not significantly change after one month of treatment in either of the groups $(P>0.05)$. After 3 and 6 months of treatment, the TDI scores both significantly increased, and the odor discrimination and identification abilities were significantly strengthened for both groups $(P<0.05)$, but the odor thresholds did not improve (Table 1 and Fig. 1).

\section{Influencing factors on the clinical effect}

The single-factor analysis revealed that the course of the disease was significantly correlated with the therapeutic effect for both groups. Patients with a shorter course of the disease (time from the onset of symptoms to the start of olfactory training) had a significantly better therapeutic effect (test group: $\mathrm{OR}=1.374$, CI: $1.135-1.663, P=0.001$; control group: OR=0.805, CI: 0.696-0.931, $P=0.004$; Table 2).

\section{DISCUSSION}

URTI is one of the common causes of olfactory dysfunction, which impacts the quality of life, social communication, and nutrient ingestion, and even causes depression or other mental problems. ${ }^{10,11}$ The possible infection mechanisms may be correlated to the following: a reduction in the number of olfactory receptors and olfactory tracts, and the loss of olfactory receptor cilium due to viral infection; the replacement of the olfactory epithelia by epithelia, or massive scaring; olfactory pathway invasion into the olfactory center caused by a neurotropic virus. As reported, URTI-induced olfactory dysfunction is dominated by hyposmia, and mainly affects women over the age of 50 years old. This may be accompanied by taste dysfunction, but not with other nasal symptoms. The Sniffin' Sticks tests mostly revealed that the deterioration of olfactory identification ability was more significant. The present study reveals that the 125 included patients are mostly females (67.2\%), aged $51.26 \pm 12.94$ years old. The olfaction psychophysics tests revealed that olfactory dysfunction was dominated by hyposmia (90 patients, $72.0 \%$ ). The TDI scores show that the deterioration of odor identification ability was more evident. These results are consistent with previous research. During clinical practice in recent years, olfactory training has been increasingly used to treat URTI-induced olfactory dysfunction. Since olfactory training is a novel method 
of olfactory dysfunction treatment, the relationship between olfactory agent selection and clinical effect should be explored and enriched by relevant medicine-based evidence. To date, the olfactory agents used in research are standardized reagents made from specialized corporations, which are stored in liquid-exclusive glass bottles, making these inconvenient for long-distance carrying. Unfortunately, many patients have to interrupt treatment, which reduces therapeutic compliance. For this reason, the investigators selected four accessible odors found in daily life (essential balm, vinegar, alcohol, and rose perfume) for the olfactory training.
In the novel treatment of olfactory training, the olfaction of the olfactory dysfunction patient is periodically irritated by olfactory agents to recover olfactory function. The review of relevant studies revealed that olfactory training may be a new effective intervention for olfactory dysfunction patients, and that its effective rate is $28 \%-63 \% .^{12}$

It is reported that olfactory training has been confirmed to be effective for patients with postinfectious olfactory loss. Besides, compared with the classical odor training group, the modified olfactory training group could improve the success rate of this therapy by increasing the duration of olfactory training and

TABLE 1. THE TDI SCORES BEFORE AND AFTER TREATMENT OF CONTROL GROUP AND TEST GROUP

\begin{tabular}{|c|c|c|c|c|c|c|c|c|}
\hline \multirow[t]{2}{*}{ Time } & \multicolumn{4}{|c|}{ Control group } & \multicolumn{4}{|l|}{ Test group } \\
\hline & $T$ & D & 1 & TDI & $\mathrm{T}$ & $\mathrm{D}$ & 1 & TDI \\
\hline Before treatment a & $6.76 \pm 1.96$ & $7.17 \pm 1.74$ & $2.88 \pm 1.51$ & $16.82 \pm 2.67$ & $6.49 \pm 2.18$ & $7.06 \pm 1.85$ & $2.82 \pm 1.60$ & $16.29 \pm 2.69$ \\
\hline 1 month after treatment $b$ & $6.88 \pm 2.15$ & $7.32 \pm 1.85$ & $2.75 \pm 1.67$ & $17.30 \pm 2.96$ & $6.57 \pm 2.05$ & $7.20 \pm 1.72$ & $2.88 \pm 1.56$ & $16.65 \pm 2.55$ \\
\hline 3 months after treatment $\mathrm{c}$ & $6.91 \pm 2.03$ & $8.70 \pm 1.96$ & $4.92 \pm 1.71$ & $20.53 \pm 3.01$ & $6.58 \pm 2.07$ & $8.63 \pm 1.92$ & $5.00 \pm 1.71$ & $20.43 \pm 2.94$ \\
\hline 6 months after treatment $d$ & $6.86 \pm 2.35$ & $9.48 \pm 2.18$ & $6.13 \pm 1.62$ & $22.48 \pm 3.73$ & $6.64 \pm 2.08$ & $9.66 \pm 2.36$ & $6.40 \pm 1.75$ & $22.88 \pm 3.90$ \\
\hline \multirow[t]{2}{*}{$T a-b(P)$} & -1.121 & -1.454 & 0.893 & -1.819 & -0.751 & -1.218 & -0.540 & -1.695 \\
\hline & $(P>0.05)$ & $P>0.05$ & $P>0.05$ & $P>0.05$ & $(P>0.05)$ & $P>0.05$ & $P>0.05$ & $P>0.05$ \\
\hline \multirow[t]{2}{*}{$\mathrm{Ta}-\mathrm{c}(\mathrm{P})$} & -1.501 & -12.091 & -11.047 & -11.065 & -0.642 & -12.103 & -14.106 & -13.067 \\
\hline & $(P>0.05)$ & $(P<0.05)$ & $(P<0.05)$ & $(P<0.05)$ & $(P>0.05)$ & $(P<0.05)$ & $(P<0.05)$ & $(P<0.05)$ \\
\hline \multirow[t]{2}{*}{ Ta-d (P) } & -0.799 & -16.134 & -17.561 & -15.400 & -1.045 & -12.953 & -18.290 & -15.233 \\
\hline & $(P>0.05)$ & $(P<0.05)$ & $(P<0.05)$ & $(P<0.05)$ & $(P>0.05)$ & $(P<0.05)$ & $(P<0.05)$ & $(P<0.05)$ \\
\hline \multirow[t]{2}{*}{$T b-c(P)$} & -0.333 & -10.609 & -13.716 & -10.893 & -0.133 & -11.920 & -13.861 & -13.450 \\
\hline & $(P>0.05)$ & $(P<0.05)$ & $(P<0.05)$ & $(P<0.05)$ & $(P>0.05)$ & $(P<0.05)$ & $(P<0.05)$ & $(P<0.05)$ \\
\hline \multirow[t]{2}{*}{ Tb-d (P) } & 0.063 & -14.755 & -20.112 & -13.257 & -0.516 & -12.956 & -18.607 & -15.170 \\
\hline & $(P>0.05)$ & $(P<0.05)$ & $(P<0.05)$ & $(P<0.05)$ & $(P>0.05)$ & $(P<0.05)$ & $(P<0.05)$ & $(P<0.05)$ \\
\hline \multirow[t]{2}{*}{ Tc-d (P) } & 0.375 & -7.176 & -8.045 & -6.765 & -0.424 & -7.090 & -8.787 & -7.918 \\
\hline & $(P>0.05)$ & $(P<0.05)$ & $(P<0.05)$ & $(P<0.05)$ & $(P>0.05)$ & $(P<0.05)$ & $(P<0.05)$ & $(P<0.05)$ \\
\hline
\end{tabular}

$a=$ before treatment, $b=1$ month after treatment, $c=3$ months after treatment, $d=6$ months after treatment

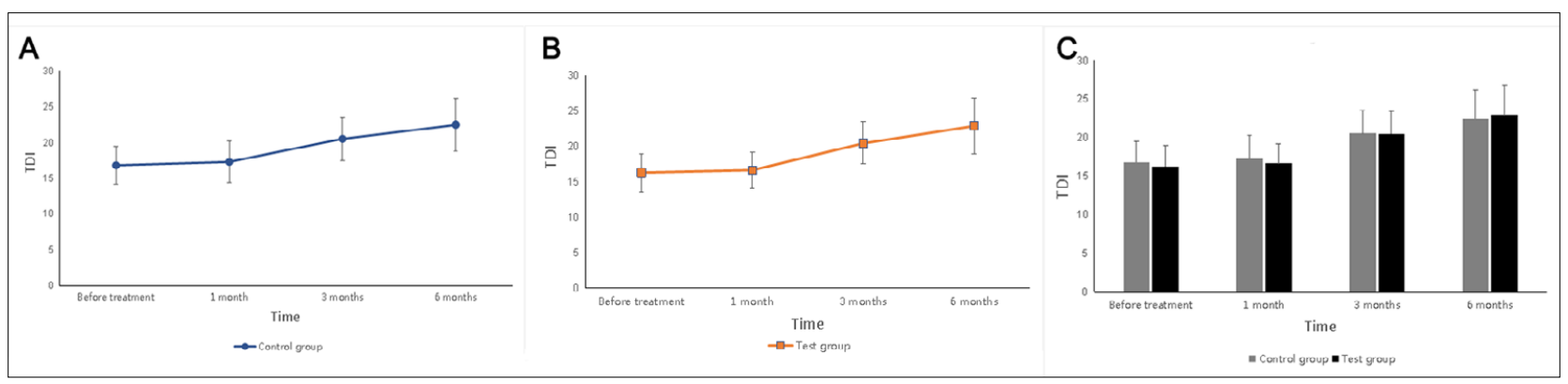

FIGURE 1. TDI SCORES DATA AND COMPARISOIN

A: TDI scores data in control group; B: TDI scores data in test group; C: Comparison of TDI scores between control and test group. 
changing the odors. ${ }^{13}$ The olfactory system of mammals can be regenerated during their whole life, and olfactory epithelia and olfactory bulbs both have strong regeneration ability. ${ }^{14} \mathrm{~A}$ higher olfactory center has moderate regeneration ability, which theoretically underlies the treatment of olfactory dysfunction by olfactory training. Recent research showed that recurrent olfactory irritation can intensify the potential reaction of olfactory epithelia, indicating that olfactory training is involved in olfactory epithelial reconstruction, probably by increasing the number of olfactory neurons in humans. ${ }^{15}$ In addition to the above direct participation, olfactory training can also significantly enlarge the volumes of olfactory bulbs ${ }^{16}$ and improve the network connection of the olfaction-related cerebral cortex ${ }^{17,18}$, indicating that olfactory training is critical in regenerating the central nervous system.

The present subjects were URTI-induced olfactory dysfunction patients who had not been cured by drugs. Since unpleasant odors vs. pleasant odors can more significantly affect the breathing mode of humans ${ }^{19}$ and reduce the work memory ability of a part of normal people ${ }^{20}$, relatively pleasant smells were selected for the present olfactory training. The effective rates at 1,3 , and 6 months after treatment were $3.08 \%, 26.15 \%$, and $41.54 \%$, respectively, in the test group, and $1.67 \%$, $26.67 \%$, and $41.67 \%$, respectively, in the control group. The therapeutic effects were not significantly different between groups at any time point $(P>0.05)$, suggesting that the two combinations of olfactory agents achieved the same therapeutic effect. The TDI scores in the $1^{\text {st }}$ month were not significantly different from those before treatment $(P>0.05)$. The scores in the $3^{\text {rd }}$ and $6^{\text {th }}$ months were both significantly higher than those before treatment $(P<0.05)$. Pertaining to the treatment period and therapeutic effect, this result can be better explained when a relatively long period of olfactory system regeneration is considered. The potential influencing factors on the clinical effect were studied via Logistic regression analysis, which revealed that the major influence factor on prognosis was the course of the disease, which is consistent with previous research..$^{21}$ The odor discrimination ability and odor identification ability were both significantly improved after 3 and 6 months of training $(P<0.05)$, but the odor threshold did not obviously improve $(P>0.05)$. In other words, the increment of TDI scores in URTI-induced olfactory dysfunction patients after the olfactory training was mainly reflected in the changes in odor discrimination and identification abilities, but not in the odor threshold. To date, most studies have held that the olfactory threshold is mediated at the olfactory epithelium level. However, functional MRI research has confirmed that olfactory training may lead to the most apparent change in the cortex..$^{22}$ Since patients with complete anosmia are nonresponsive to olfactory irritation, it is impossible to use odor excitement to activate the olfactory functions of olfactory epithelia and the brain. The olfactory system is closely correlated to the nasal trigeminal nerve system, and most odors not only irritate the smell neurons but also activate the trigeminal nervous system..$^{23,24}$ Moreover, the nasal trigeminal nervous system is largely involved in olfactory signal processing, such as odor laterality identification and odor intensity assisted identification. ${ }^{23,25,26}$ Thus, olfactory training can improve the odor discrimination and identification abilities of olfactory dysfunction patients, which may be correlated to the deep

TABLE 2.REGRESSION ANALYSIS OF INFLUENCE FACTORS CORRELATED WITH THE CLINICAL EFFECT

\begin{tabular}{|c|c|c|c|c|c|c|}
\hline \multirow[t]{2}{*}{ Factor } & \multicolumn{3}{|c|}{ Control group } & \multicolumn{3}{|c|}{ Test group } \\
\hline & OR & $95 \% \mathrm{Cl}$ & $P$ & OR & $95 \% \mathrm{Cl}$ & $P$ \\
\hline Gender & 0.572 & $0.142 \sim 2.306$ & 0.432 & 1.842 & $0.425 \sim 7.985$ & 0.414 \\
\hline Age & 0.979 & $0.927 \sim 1.033$ & 0.435 & 1.009 & $0.958 \sim 1.062$ & 0.745 \\
\hline BMI & 1.954 & $0.545 \sim 7.010$ & 0.304 & 0.284 & $0.068 \sim 1.188$ & 0.284 \\
\hline Course of disease & 0.805 & $0.696 \sim 0.931$ & 0.004 & 1.374 & $1.135 \sim 1.663$ & 0.001 \\
\hline History of smoking/drinking & 2.558 & $0.448 \sim 14.601$ & 0.290 & 0.305 & $0.055 \sim 1.711$ & 0.305 \\
\hline Complicated with taste dysfunction & 1.795 & $0.462 \sim 6.979$ & 0.399 & 0.864 & $0.212 \sim 3.515$ & 0.838 \\
\hline VAS score & 0.988 & $0.702 \sim 1.389$ & 0.943 & 1.066 & $0.713 \sim 1.593$ & 0.755 \\
\hline Diabetes & 2.821 & $0.601 \sim 13.237$ & 0.188 & 1.386 & $0.254 \sim 7.556$ & 0.706 \\
\hline Hypertension & 1.492 & $0.356 \sim 6.258$ & 0.584 & 0.461 & $0.108 \sim 1.964$ & 0.295 \\
\hline Preoperative TDI & 1.061 & $0.825 \sim 1.364$ & 0.644 & 1.056 & $0.82 \sim 1.354$ & 0.671 \\
\hline
\end{tabular}


participation of the nasal trigeminal nervous system. Based on these present results, it has been speculated that different types of olfactory agents may function similarly in irritating the olfactory system and nasal trigeminal system. The involvement of the trigeminal nervous system is one of the possible mechanisms for stimulating the olfactory system. There may be other mechanisms to stimulate the olfactory system. However, this needs to be confirmed through more relevant research.

Overall, these two combinations of olfactory agents are effective interventions for URTI-induced olfactory dysfunction that can significantly improve the odor discrimination and identification abilities. The inclusion rate of the test group was significantly higher than that of the control group, mainly due to the inconvenience of carrying the agents and economic reasons. When odors that can be easily obtained in daily life (e.g., essential balm, vinegar, alcohol, and rose perfume) were used in olfactory training, a similar clinical effect to the control group was achieved. Furthermore, since low cost and portability would increase patient compliance, the clinical use of these odors is recommended. Moreover, the prolonged and earlier start of olfactory training would be more helpful for the recovery of olfactory functions.

\section{RESUMO}

OBJETIVO: Comparar duas combinações de agentes olfativos para uso em terapia de treinamento olfativo no tratamento de disfunção olfatória após infecção do trato respiratório superior (ITRS) e investigar os fatores que influenciam os efeitos clínicos.

METODOLOGIA: 125 pacientes com disfunção olfativa foram divididos aleatoriamente em dois grupos: teste e controle. Durante o treinamento olfativo, quatro odores foram utilizados em ambos os grupos. O treinamento olfativo durou 24 semanas. Em seguida, os participantes foram testados usando Sniffin' Sticks e o escore de discriminação, limiar e identificação (TDI) antes do tratamento e 1, 3 e 6 meses após o ele. Os escores de TDI foram comparados em momentos diferentes, entre os grupos e dentro deles, e os fatores de influência foram analisados.

RESULTADOS: Não houve diferença significativa nos escores de TDI entre os dois grupos. Além disso, os escores de TDI não demonstração nenhuma alteração significa após um mês de tratamento em ambos os grupos. Após 3 e 6 meses de tratamento, ambos os escores de TDI aumentaram significativamente, e as habilidades de identificação e discriminação de odores melhoraram significativamente em ambos os grupos; contudo, os limiares de odor não demonstraram melhora. O curso da doença foi um importante fator de influência no efeito terapêutico do treinamento olfativo em ambos os grupos.

CONCLUSÃo: A combinação de bálsamo essencial, vinagre, álcool, e perfume de rosas no treinamento olfativo, todos aromas comumente encontrados na vida cotidiana, podem efetivamente curar disfunção olfativa induzida por ITRS e melhorar significativamente as habilidades de discriminação e identificação de odores. Além disso, a prolongamento do tempo de tratamento pode ajudar na recuperação das funções olfativas, e o início antecipado do treinamento olfativo pode melhorar o efeito terapêutico.

PalaVRas Chave: Transtornos do Olfato. Percepção Olfatória. Capacitação. Olfato/fisiologia. Infecção.

\section{REFERENCES}

1. Fonteyn S, Huart C, Deggouj N, Collet S, Eloy P, Rombaux P. Non-sinonasal-related olfactory dysfunction: a cohort of 496 patients. Eur Ann Otorhinolaryngol Head Neck Dis. 2014;131(2):87-91.

2. Patel $Z M$. The evidence for olfactory training in treating patients with olfactory loss. Curr Opin Otolaryngol Head Neck Surg. 2017;25(1):43-6.

3. Boesveldt S, Postma EM, Boak D, Welge-Luessen A, Schöpf V, Mainland JD, et al. Anosmia: a clinical review. Chem Senses. 2017;42(7):513-23.

4. Sorokowska A, Drechsler E, Karwowski M, Hummel T. Effects of olfactory training: a meta-analysis. Rhinology. 2017;55(1):17-26.

5. Schriever VA, Lehmann S, Prange J, Hummel T. Preventing olfactory deterioration: olfactory training may be of help in older people. J Am Geriatr Soc. 2014;62(2):384-6.

6. Hummel T, Rissom K, Reden J, Hähner A, Weidenbecher M, Hüttenbrink KB. Effects of olfactory training in patients with olfactory loss. Laryngoscope. 2009;119(3):496-9.

7. Gudziol V, Lötsch J, Hähner A, Zahnert T, Hummel T. Clinical significance of results from olfactory testing. Laryngoscope. 2006;116(10):1858-63.

8. Deems DA, Doty RL, Settle RG, Moore-Gillon V, Shaman P, Mester AF, et al. Smell and taste disorders, a study of 750 patients from the University of
Pennsylvania Smell and Taste Center. Arch Otolaryngol Head Neck Surg. 1991;117(5):519-28.

9. Subspecialty Group of Rhinology, Editorial Board of Chinese Journal of Otorhinolaryngology Head and Neck Surgery; Subspecialty Group of Rhinology, Society of Otorhinolaryngology Head and Neck Surgery, Chinese Medical Association. Expert consensus on diagnosis and treatment of olfactory dysfunction (2017). Zhonghua Er Bi Yan Hou Tou Jing Wai Ke Za Zhi. 2018;53(7):484-94.

10. Hummel T, Whitcroft KL, Andrews P, Altundag A, Cinghi C, Costanzo RM, et al. Position paper on olfactory dysfunction. Rhinol Suppl. 2017;54(23):1-30.

11. Croy I, Schulz M, Blumrich A, Hummel C, Gerber J, Hummel T. Human olfactory lateralization requires trigeminal activation. Neuroimage. 2014;98:289-95.

12. Poletti SC, Michel E, Hummel T. Olfactory training using heavy and light weight molecule odors. Perception. 2017;46(3-4):343-51.

13. Altundag A, Cayonu M, Kayabasoglu G, Salihoglu M, Tekeli H, Saglam O, et al. Modified olfactory training in patients with postinfectious olfactory loss. Laryngoscope. 2015;125(8):1763-6.

14. Brann JH, Firestein SJ. A lifetime of neurogenesis in the olfactory system. Front Neurosci. 2014;8:182. 
15. Wang $L$, Chen $L$, Jacob T. Evidence for peripheral plasticity in human odour response. J Physiol. 2004;554(Pt 1):236-44.

16. Negoias $S$, Pietsch K, Hummel T. Changes in olfactory bulb volume following lateralized olfactory training. Brain Imaging Behav. 2017;11(4):998-1005.

17. Kollndorfer K, Fischmeister FP, Kowalczyk K, Hoche E, Mueller CA, Trattnig $\mathrm{S}$, et al. Olfactory training induces changes in regional functional connectivity in patients with long-term smell loss. Neuroimage Clin. 2015;9:401-10.

18. Kollndorfer K, Kowalczyk K, Hoche E, Mueller CA, Pollak M, Trattnig S, et al. Recovery of olfactory function induces neuroplasticity effects in patients with smell loss. Neural Plast. 2014;2014:140419.

19. Ferdenzi C, Fournel A, Thévenet M, Coppin G, Bensafi M. Viewing olfactory affective responses through the sniff prism: effect of perceptual dimensions and age on olfactomotor responses to odors. Front Psychol. 2015;6:1776.

20. Martin GN, Chaudry A. Working memory performance and exposure to pleasant and unpleasant ambient odor: is spatial span special? Int j Neurosci. 2014;124(11):806-11.

21. Yan XG, Gao X, Sun ZF, Guo YC, Yao LY, Liu J, et al. Efficacy and associated factors of olfactory training in the treatment of olfactory dysfunction. Zhonghua Er Bi Yan Hou Tou Jing Wai Ke Za Zhi. 2018;53(11):815-9.

22. Pekala K, Chandra RK, Turner JH. Efficacy of olfactory training in patients with olfactory loss: a systematic review and meta-analysis. Int Forum Allergy Rhinol. 2016;6(3):299-307.

23. Croy I, Nordin S, Hummel T. Olfactory disorders and quality of life: an updated review. Chem Senses. 2014;39(3):185-94.

24. Albrecht |, Kopietz R, Frasnelli I, Wiesmann M, Hummel T, Lundström JN. The neuronal correlates of intranasal trigeminal function-an ALE meta-analysis of human functional brain imaging data. Brain Res Rev. 2010;62(2):183-96.

25. Walliczek-Dworschak U, Poncelet |, Baum D, Baki R, Sinding C, Warr ], et al. The presentation of olfactory-trigeminal mixed stimuli increases the response to subsequent olfactory stimuli. J Agric Food Chem. 2018;66(10):2312-8.

26. Reichert IL, Schöpf V. Olfactory loss and regain: lessons for neuroplasticity. Neuroscientist. 2018;24(1):22-35. 